\title{
THE EFFICIENCY OF NON-FLAMMABLE FUNCTIONAL UNDERWEAR
}

\author{
Viera Glombikova, Petra Komarkova \\ Technical University of Liberec, Faculty of Textile Engineering, Department of Clothing Technology, \\ Liberec, Czech Republic, Studentska 1402/2, 461 17, Liberec, \\ tel. +420 485353 124, fax. +420 485353 204, e-mail: viera.glombikova@tul.cz
}

\begin{abstract}
:
This study evaluates the efficiency of non-flammable functional underwear used as a secondary heat barrier in extreme conditions. Five groups of knitted fabrics were analysed for flame resistance and selected physiological properties (water vapour permeability, air permeability, thermal resistance and liquid moisture transport by moisture management transport). The results indicated similar levels of flame resistance for the materials tested but show important differences in terms of physiological characteristics, namely liquid moisture transport, which influences the safety and comfort of protective clothing.
\end{abstract}

\section{Keywords:}

Functional underwear, physiological comfort, flame resistance, moisture management transport

\section{Introduction}

Non-flammable functional underwear is used as a secondary heat barrier and, together with an outer layer of protective clothing, provides optimal required protection in extreme conditions for workers such us fire fighters, soldiers, policemen and industrial workers (in the metallurgical, oil, chemical industry, etc.). Apart from flame resistance, the physiological comfort of the underwear is one of the most significant factors for ensuring the best conditions for the wearer while they are active [9].

Currently, special highly functional knitted fabrics are generally used for the production of non-flammable underwear. These fabrics are made from different types of non-flammable or flame retardant materials $[2,15]$. The efficiency of flame-resistant fabrics depend on the type of fibres used especially their LOI (limiting oxygen index), the blend ratio of the material, the fabric structure and last but not the least, on the finishing procedures, especially for blends containing cotton $[3,6,8,13,16]$. The structure of the fabric (weight, thickness, course and wale density, number of yarn in a loop, etc.) influences both its flame resistance and the overall physiological and thermal comfort of the protective clothing. This comfort factor is dictated by the fabric's physiological properties, such as water vapour resistance, air permeability and thermal resistance $[4,9,10]$. Depending on the thermal insulation value and the type and duration of activity, the minimum and maximum ambient temperatures for using the protective clothing may be estimated. Low water vapour resistance and high air permeability promote the evaporation of perspiration and, thereby, the cooling of the body. These properties improve the wearing comfort and reduce physiological stress [5]. High water vapour permeability refers to the ability to transmit vapour quickly away from the body. If the combination of protective clothing layers cannot transport sweat in vapour form away from the skin sufficiently quickly, sweat condenses on the skin (or inner fabric surface). In which case, the underwear should transmit this moisture away from the skin or inner fabric surface to the outer surface as soon as possible for the protection and comfort of the users. Therefore, dynamic liquid/moisture transport is very important to reduce the humidity on the surface of the skin $[7,12,14]$. Material and structure parameters (gauge and stitch length) especially influence moisture management of knitting fabric [11].

The main aim of this study is to analyse and compare selected materials for both flame resistance and physiological comfort.

\section{Experimental}

\subsection{Materials}

Five groups of knitted fabrics (made of different types of fibres, see Table 1) were analysed both for flame resistance and physiological comfort. These functional fabrics are commonly used for the production of non-flammable underwear and are available on the Czech market. It was not possible to obtain the set of materials with minimum one common property.

All experiments were carried out in a standard atmosphere for testing according to Standard ISO 139:2002.

\subsection{Methods}

The flammability and thermal properties of the knitted fabrics were investigated by four methods:

(i) According to Standard EN ISO 6942:2002 - Protective clothing - Protection against heat and fire - Method of test: Evaluation of materials and material assemblies when exposed to a source of radiant heat. 
Table 1. Characteristics of selected fabrics.

\begin{tabular}{|c|c|c|c|c|c|c|}
\hline \multicolumn{3}{|r|}{ Fabric } & \multirow{2}{*}{$\begin{array}{l}\text { Pattern } \\
\text { Interlock }\end{array}$} & \multirow{2}{*}{$\begin{array}{c}\begin{array}{c}\text { Density } \\
\left(\text { courses } \times \text { wales } / \mathrm{dm}^{-1}\right)\end{array} \\
150 \times 125\end{array}$} & \multirow{2}{*}{$\begin{array}{c}\begin{array}{c}\text { Weight } \\
\left(\mathrm{g} / \mathrm{m}^{2}\right)\end{array} \\
140\end{array}$} & \multirow{2}{*}{$\begin{array}{c}\text { Thickness } \\
\text { (mm) } \\
0.83\end{array}$} \\
\hline A & & 100\% Polypropylene & & & & \\
\hline \multirow{2}{*}{ B } & Front & $80 \%$ FR Viscose/20\% Cotton & \multirow{2}{*}{ Loop } & \multirow{2}{*}{$110 \times 75$} & \multirow{2}{*}{186} & \multirow{2}{*}{0.94} \\
\hline & Back & $50 \%$ polyoxadiazol/ 50\% FR Viscose & & & & \\
\hline C & \multicolumn{2}{|r|}{$60 \%$ FR Modacrylic/40\% Cotton } & Double jersey & $140 \times 140$ & 164 & 0.69 \\
\hline D & \multicolumn{2}{|r|}{$50 \%$ FR Viscose $/ 50 \%$ Kermel } & Interlock & $130 \times 130$ & 260 & 1.24 \\
\hline $\mathbf{E}$ & \multicolumn{2}{|c|}{$\begin{array}{c}60 \% \text { FR Modacrylic/38\% Cotton/2\% antistatic } \\
\text { fibre }\end{array}$} & Double jersey & $160 \times 180$ & 220 & 0.92 \\
\hline
\end{tabular}

Note: To keep know-how in the competitive environment on the market, it was not possible to obtain information about non-flammable treatment of the fabric from producers.

(ii) According to Standard EN ISO 6940:2004 - Textile fabrics - Burning behaviour - Determination of ease of ignition of vertically oriented specimens.

(iii) According to Standard EN ISO 15025:2002 - Protective clothing - Method of test for limited flame spread.

(iv) A bespoke method to evaluate the burnt patch of the tested materials by image analysis (see Figure 1).

Radiation heat resistance was determined according to EN ISO 6942 - method B, i.e. the protective effect of the materials was determined. A specimen is supported in a freestanding frame (specimen holder) and is exposed to a specific level of radiant heat. The time taken for the temperature to rise from $12^{\circ} \mathrm{C}$ to $24^{\circ} \mathrm{C}$ in the calorimeter is recorded and is expressed as the radiant heat transfer index. The heat transmission factor TF (\%) was calculated from the temperature rise data (see Figure 2).

The burning behaviour of the fabrics, namely the ease of ignition of vertically oriented specimens, was investigated using EN ISO 6940. Samples were placed in a rectangular frame in a vertical position. They were placed for 1-20 seconds in contact with a flame situated perpendicularly to the sample surface (as used in this study) or directly below the sample edge. If the sample ignites, the ignition time is recorded and then the mean ignition time (five instances of ignition are obtained) is determined.
Based on the burnt patches of the tested materials (that were taken using the aforementioned test, EN ISO 6940) the authors proposed an additional method to evaluate the flame resistance of the tested materials using image analysis. The dimensions of the burnt patch, such as length, perimeter and area, were measured after certain time exposure (contact fabrics with flame - flame application time) at 40, 60 and 90 sec.

Further flammability properties of all the fabrics were measured using the edge-burning method according to EN ISO 15025:2002. The samples were exposed to a small flame coming from a gas burner for 10 seconds. Then, the time of further burning and further glowing was taken as the

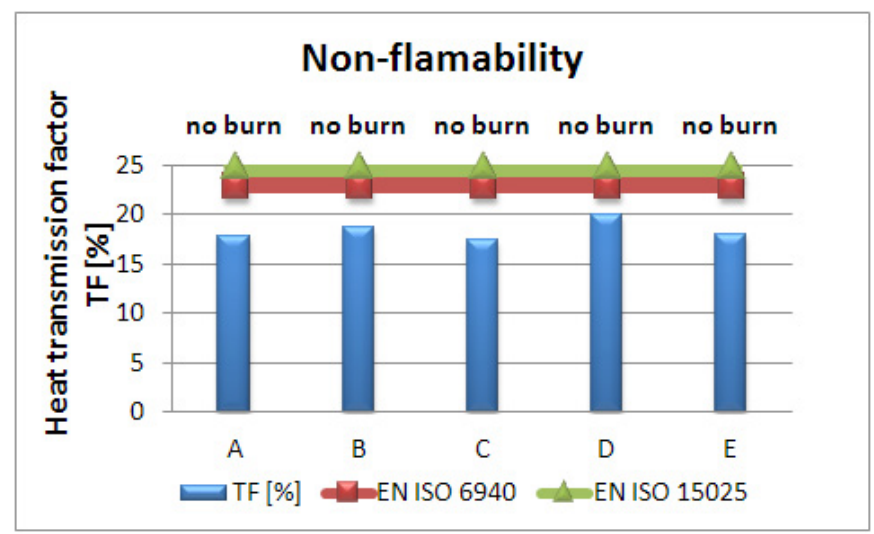

Figure 2. Evaluation of non-flammable materials according to results of Standards EN ISO 6942 (TF [\%]), EN ISO 6940 and EN ISO 15025.

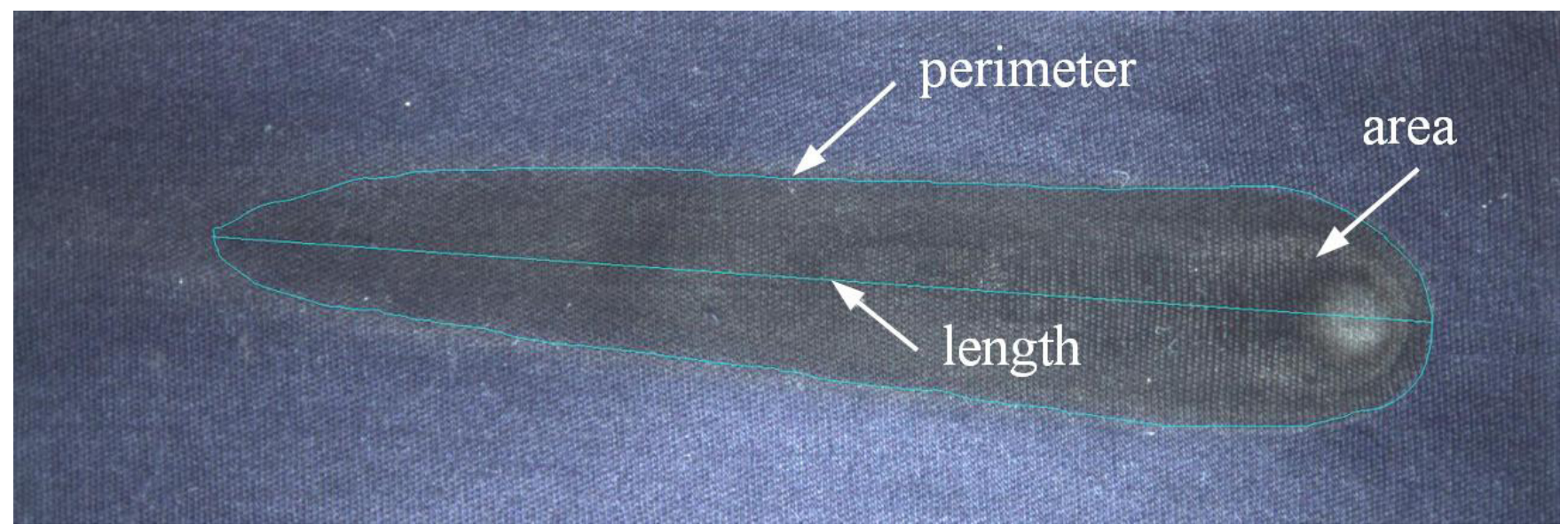

Figure 1. Burnt area evaluation by image analysis system. 
highest value registered for samples cut in warp and weft directions.

A fabric's physiological comfort can be measured as a combination of its thermal properties (such as thermal resistance and thermal conductivity), air permeability and moisture transport (both in liquid and water vapour form) [6]. Flame-retardant fibres (or treated fibres or fabrics with special flame resistant chemicals), which are commonly used in the production of non-flammable fabrics, can negatively affect both constituent physiological properties of fabrics and the overall physiological comfort for the wearer. Therefore, the physiological properties of the fabrics were investigated using the following methods:

(i) The water vapour resistance (Ret $\left.\left[\mathrm{m}^{2} \mathrm{PaW}{ }^{1}\right]\right)$ and thermal resistance (Rct $\left[\mathrm{m}^{2} \mathrm{KW}^{1}\right]$ ) were assessed according to Standard EN 31092:1993 by the Sweating Guarded Hotplate (SGHP) method.

(ii) The liquid moisture transport properties were assessed using the Moisture Management Tester per AATCC test method 195-2012.

(iii) The fabric permeability to air $\left(\mathrm{R}\left[\mathrm{mms}^{1}\right]\right)$ was determined according to Standard EN ISO 9237:1995.

The basic principles of measurement using the SGHP method and the air permeability tester are well known. The conditions for SGHP were set to: hotplate temperature $35^{\circ} \mathrm{C}$, air temperature 20 ${ }^{\circ} \mathrm{C}$ (temperature of chamber) measured $15 \mathrm{~mm}$ above the working platform, relative humidity $65 \%$, and air flow speed $1 \mathrm{~m} / \mathrm{s}$. Air permeability was investigated using a pressure of $100 \mathrm{~Pa}$.

Detailed analysis was made of the instrument for measuring the liquid moisture transport properties in multidimensions called Moisture Management Tester (hereinafter MMT). Liquid moisture transfer in clothing significantly affects the wearer's perception of moisture comfort $[1,7,14]$. The MMT was developed to quantify dynamic liquid transport properties of knitted and woven fabrics through the following three dimensions:

- Absorption rate - moisture absorbing time of the fabric's inner and outer surfaces.

- One-way transportation capability - one-way transfer from the fabric's inner surface to its outer surface.
- Spreading/drying rate - speed at which liquid moisture spreads across the fabric's inner and outer surfaces.

MMT consists of upper and lower concentric moisture sensors. The specimen is held flat under a fixed pressure between the sensors, whereas the standard test solution is introduced on to the top surface of the fabric. Electrical resistance changes between the upper and lower sensors are then recorded dynamically. Based on the electrical resistance changes, several parameters are determined. These parameters are described in detail in Hu's work [7,12,14]. Two parameters were analysed in this study: OMMC [-] - the overall moisture management capacity and OWTC [-] - cumulative one-way transport capacity, see Figures 6 and 7.

The coefficients of variation for all the tests do not exceed $5 \%$ and are therefore not statistically significant.

\section{Results and discussion}

\subsection{Flame resistance analysis of tested fabrics}

The results of the above-mentioned non-flammability tests (EN ISO 6942, EN ISO 6940 and EN ISO 15025) showed that the tested knitted fabrics meet the requirements of the set standards at very similar levels - no ignition after contact with flame application time $20 \mathrm{sec}$ (EN ISO 6940) and 10 sec. (EN ISO 15025) and very little differences in terms of heat transmission factor TF [\%] (see Table 2 and Figure 2). In summary, the materials provide high protection and are suitable for use in the production of non-flammable underwear.

Standard EN ISO 6940 for the evaluation of a fabric's flame resistance was originally designed for traditional textile materials. Some measurement conditions of the abovementioned test (flame application time, rake angle of the burner, etc.) do not fit the purpose of the fabric's usage and their flammability properties. Therefore, an additional method of flame resistance evaluation using image analysis was proposed to detect differences in non-flammability in the materials, which exhibited the same or very similar levels of flame resistance. The flame application time was set to 40 , 60 and $90 \mathrm{sec}$, and subsequent evaluation of the burnt patch of the tested materials (i.e. measurement of length, area and perimeter (see Figure 1) was carried out using the image

Table 2. Flammability results in compliance with EN ISO 15025, EN ISO 6940 and EN ISO 6942.

\begin{tabular}{|c|c|c|c|c|c|}
\hline & \multicolumn{2}{|c|}{ EN ISO 6940 (surface ignition) } & \multicolumn{2}{c|}{ EN ISO 15025 (edge ignition) } & EN ISO 6942 \\
\hline Fabric & $\begin{array}{c}\text { Flame application } \\
\text { time (s) }\end{array}$ & Ignition time (s) & $\begin{array}{c}\text { Flame application } \\
\text { time (s) }\end{array}$ & Ignition time (s) & $\begin{array}{c}\text { Heat transmission } \\
\text { factor, TF [\%] }\end{array}$ \\
\hline A & & & & & 17.74 \\
\hline B & \multirow{2}{*}{20} & $\begin{array}{c}0 \\
\text { (no ignition) }\end{array}$ & 10 & $\begin{array}{c}0 \\
\text { (no ignition) }\end{array}$ & 18.75 \\
\hline C & & & & & 17.46 \\
\hline D & & & & & 20.05 \\
\hline E & & & & & 18.03 \\
\hline
\end{tabular}


analysis system, 'NIS - Elements'. The results of this analysis are presented in Table 3 and the averages of all parameters (for all flame application times) are plotted in the graph (see Figure 3).

According to this analysis, fabric $\mathrm{C}$ (made of a FR modacrylic/ cotton blend) was assessed to be the best. Fabric $C$ showed the least area, perimeter and length of burnt patch from all the tested fabrics. Fabric $\mathrm{C}$ exhibited about $55 \%$ lower area value than fabric $B$, i.e. flame protection fabric $C$ is better.

\subsection{Physiological comfort analysis of tested fabrics}

This section describes the evaluation of the physiological properties of tested knitted fabrics. Although the results presented in Figures 4 and 5 demonstrated that the fabrics exhibit very similar levels in terms of their thermal resistance (Rct), air permeability (R) and water vapour resistance (Ret), there are differences in terms of liquid moisture transport through the tested functional fabrics by MMT. Material $C$ showed the best value of OMMC (Overall Moisture Management Capability) and OWTC (Cumulative One-Way Transport Capacity), i.e. this one can efficiently transport sweat from the skin to the outer surface of the fabrics or to outer layers or the environment (see Figures 6 and 7). It is especially important when the other clothing layers (for example, fire fighters emergency jacket)

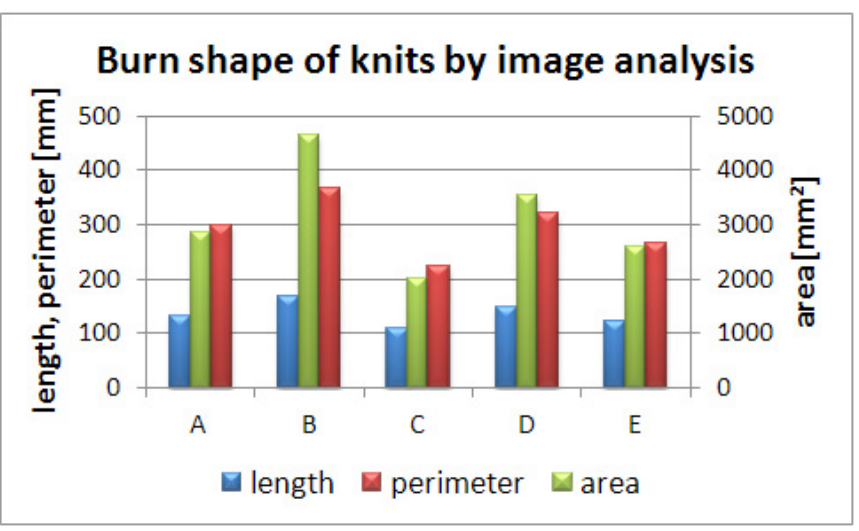

Figure 3. Evaluation of burnt patch of tested material by image analysis method. cannot transport the sweat away in the form of water vapour sufficiently quickly (during thermoregulation of body) and the sweat condenses to liquid under this clothing layer. The role of underwear fabrics is to transport condensed liquid from the surface of the skin and to ensure the physiological comfort of the wearer.

Note: OWTC is defined as the difference in the cumulative moisture content between the two surfaces of the fabric. Negative values mean that the cumulative moisture content on the inner surface of the fabric is higher than on the outer surface (see Figure 7 - fabric D).

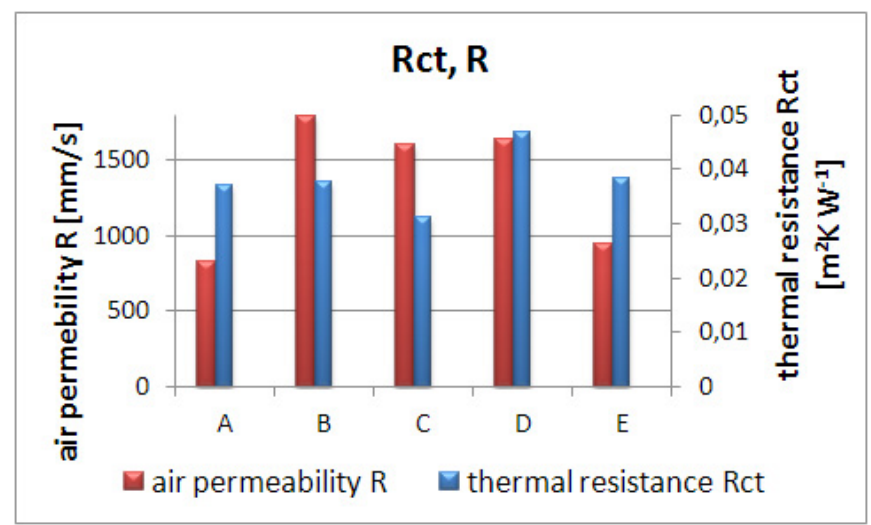

Figure 4. Evaluation of tested materials in terms of their thermal resistance (Rct) and air permeability (R).

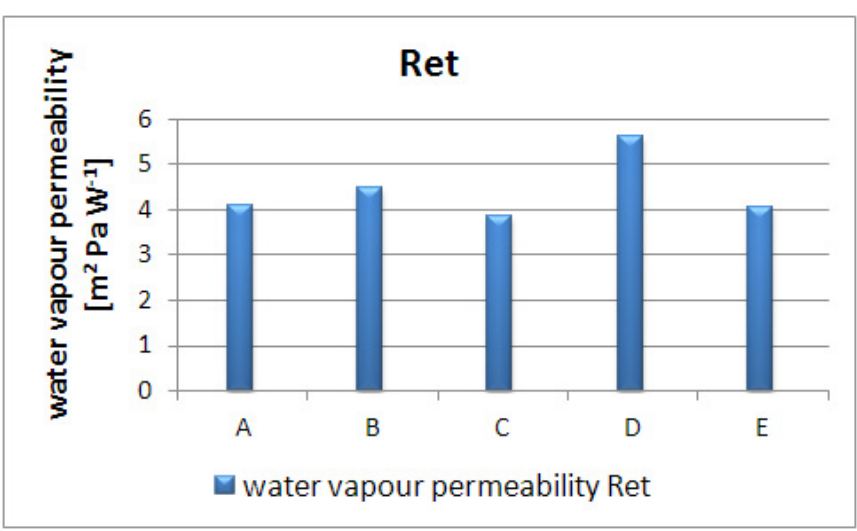

Figure 5. Results of water vapour permeability (Ret) of tested fabrics.

Table 3. Results of burnt patch evaluation of tested fabrics by image analysis method.

\begin{tabular}{|c|c|c|c|c|c|c|c|c|c|c|}
\hline & & \multicolumn{3}{|c|}{ Length [mm] } & \multicolumn{3}{|c|}{ Perimeter [mm] } & \multicolumn{3}{|c|}{ Area [mm2] } \\
\hline \multicolumn{2}{|c|}{$\begin{array}{c}\text { Fabric/statistical characteristics/flame } \\
\text { application time [sec] }\end{array}$} & 40 & 60 & 90 & 40 & 60 & 90 & 40 & 60 & 90 \\
\hline \multirow{2}{*}{ A } & Mean & 127 & 135 & 136 & 291 & 296 & 299 & 2798 & 2845 & 2851 \\
\hline & Standard deviation & 5.2 & 3.8 & 7.4 & 10.1 & 6.3 & 8.5 & 84.3 & 35.9 & 92.3 \\
\hline \multirow{2}{*}{ B } & Mean & 166 & 170 & 172 & 360 & 369 & 371 & 4485 & 4723 & 4750 \\
\hline & Standard deviation & 4.5 & 1.4 & 6.8 & 9.7 & 5.8 & 10.2 & 75.0 & 27.3 & 55.3 \\
\hline \multirow{2}{*}{ C } & Mean & 106 & 110 & 112 & 218 & 223 & 231 & 1942 & 1960 & 2096 \\
\hline & Standard deviation & 3.2 & 10.9 & 7.9 & 2.3 & 16.8 & 12.5 & 105.1 & 98.4 & 86.8 \\
\hline \multirow{2}{*}{ D } & Mean & 146 & 147 & 150 & 317 & 325 & 325 & 3486 & 3528 & 3601 \\
\hline & Standard deviation & 5.9 & 1.9 & 10.4 & 8.8 & 5.2 & 9.4 & 124.1 & 42.5 & 156.3 \\
\hline \multirow{2}{*}{$\mathbf{E}$} & Mean & 121 & 123 & 126 & 267 & 265 & 270 & 2570 & 2598 & 2621 \\
\hline & Standard deviation & 3.5 & 2.6 & 11.9 & 9.2 & 1.0 & 15.3 & 72.8 & 24.5 & 142.2 \\
\hline
\end{tabular}




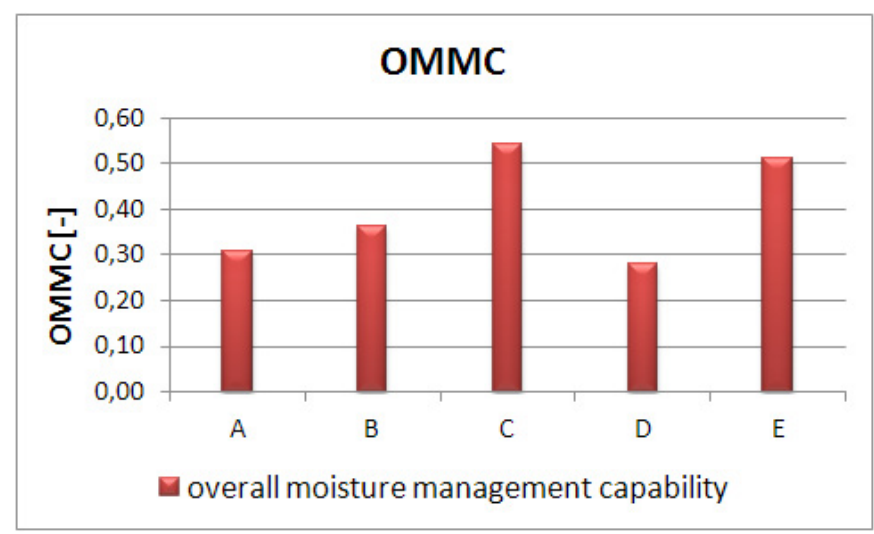

Figure 6. Results of overall moisture management capability (OMMC) of tested materials measured by MMT.

\section{Conclusions}

Many of the standards for the evaluation of the flame resistance of fabrics (e.g. EN ISO 6940, EN ISO 15025) were originally designed for traditional burnable materials. Some conditions of the aforementioned tests (flame application time, rake angle of burner, etc.) do not fit the purpose of the fabric's usage (as the protective materials) and their flammability properties. Therefore, an additional method of flame resistance evaluation using image analysis was proposed to detect non-flammability differences between the tested materials.

Generally, not only the flame resistance but also the physiological comfort of the protective clothing is very significant in terms of the overall wearer performance, such as fire fighter or industry workers (for metallurgical, oil, chemical industry, etc.). One of the most important physiological fabric characteristics of non-flammable functional underwear is the speed at which liquid moisture is transported through the fabric and the spreading dynamics of moisture (sweat) on the inner and outer fabric surfaces. This property at an appropriate level completes the set of physiological characteristics required to optimize the properties of functional underwear.

In summary, although flame resistance is the basic primary property, it is also necessary to take into account the physiological parameters that increase the safety and comfort of the user.

\section{Acknowledgements}

This research work was supported through Technology Agency of the Czech Republic Project No. TA01011253. The authors thank Kristyna Kudelkova for her assistance in tests of experiment.

\section{References}

[1] Bao-guo, Y., et al. (2006). An improved test method for characterizing the dynamic liquid moisture transfer in porous polymeric materials. Polymer Testing, 25 (5), pp. 677-689.

[2] Bourbigot, S. and Flambard, X. (2002). Heat Resistance and Flammability of High Performance Fibres: A Review, Fire And Materials, 26 (4-5), pp. 155-168.

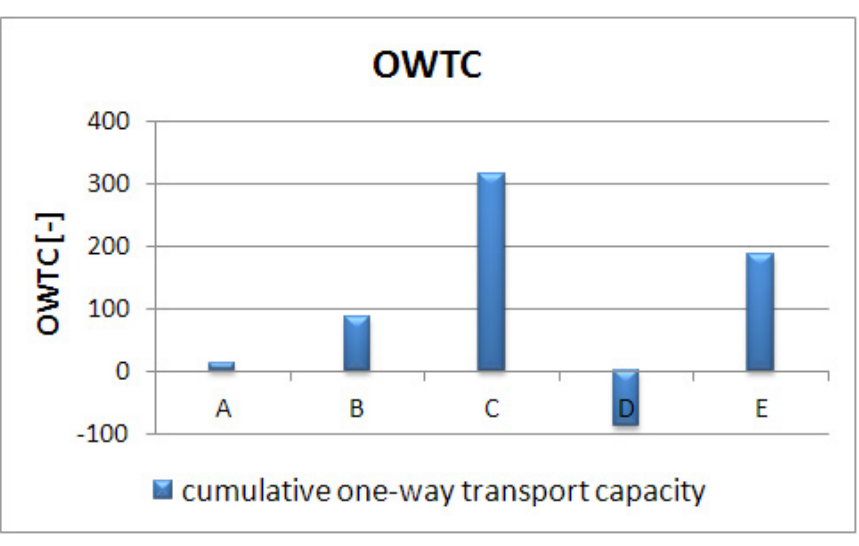

Figure 7. Results of cumulative one-way transport capacity (OWTC) of tested materials measured by MMT.

[3] Cardoso, I., an Gomes, J. R. (2009). The application of microcapsules of PCM in flame resistant non-woven materials, International Journal of Clothing Science and Technology, 21 (2/3), pp. 102-108

[4] Havelka, A., Kus, Z. (2012). Innovations in Textile materials \&Protective clothing. Monograph, Warsaw, Technical university of Lodz press. The importance of moisture transport in the insulating properties of sandwich structures, smart clothes. ISBN 978-83-7283-493-5, pp. 137-144.

[5] Heffels, P. (2006). Protective clothing against rain or low temperatures - overview of European standards, 3rd European Conference on Protective Clothing (ECPC), Gdynia, Poland

[6] House, J. R., (2004). Effectiveness of Proban® flame retardant in used clothing, International Journal of Clothing Science and Technology , 16 (4), pp. 361-367

[7] Hu, J. et al. (2005). Moisture Management tester: A Method to Characterize Fabric Liquid Moisture Management properties, Textile Research Journal, 75 (1),pp. 57-62

[8] Mamalis, P. (2001). The effect of a durable flame-retardant finishing on the mechanical properties of cotton knitted fabrics, International Journal of Clothing Science and Technology, 13 (2), pp. 132-134

[9] Mikucioniene, D. et al. (2012). Influence of plan Knits Structure on Flammability and Air Permeability, Fibres \& Textile in Eastern Europe, 20 (5), pp.66-69

[10] Mikucioniene, D. et al. (2011). Influence of the Number of Yarns in a Loop on the Flammability of Knits, Fibres \& Textile in Eastern Europe, 19 (6), pp.71-74

[11] Nazir, A., et al.(2014), Effect of Knitting Parameters on Moisture Management and Air Permeability of Interlock Fabrics, AUTEX Research Journal, 14(1), pp.39-46

[12] Oner, E., et al. (2013). Evaluation of Moisture Management Properties on knitted fabrics, Journal of the Textile Institute, 104 (7), pp.699-707

[13] Ozcan, G., et al. (2004). Impact of Finishing Processes on Flame Resistance of Knitted Fabric, Textile Research Journal, 74`(6), pp. 490-496.

[14] Troynikov, O., Wardiningsih, W. (2011). Moisture management properties of wool/polyester and wooll bamboo knitted fabrics for the sportswear base layer, Textile Research Journal, 2011, 81(6), pp. 621-631.

[15] Varga, K., et al. (2011). Thermal and Sorption Study of Flame-resistant Fibres., LenzingerBerichte, 89, pp.50-59

[16] Weil, E. D. and Levchnik, S. V., (2008). Flame retardants in Commercial Use or Development for Textiles, Journal of Fire Sciences, 26 (3), pp. 243-281. 